\title{
A SCOPING SURVEY OF ATTITUDES TOWARDS OCCUPATIONAL EXPOSURE LIMITS AND REACH DERIVED NO EFFECT LEVELS FOR WORKERS AMONG CHEMICAL RISK MANAGERS AT SWEDISH WORKPLACES
}

\author{
LINDA SCHENK ${ }^{1,2}$ \\ ${ }^{1}$ Karolinska Institutet, Stockholm, Sweden \\ Integrative Toxicology, Institute of Environmental Medicine \\ ${ }^{2}$ Royal Institute of Technology, Stockholm, Sweden \\ Department of Philosophy and History
}

\begin{abstract}
Objectives: Setting and implementing occupational exposure limits (OELs) is one of the measures taken to protect workers from adverse effects of hazardous chemicals. The EU Regulation on Registration, Evaluation, Authorisation and Restriction of Chemicals (REACH) introduced an additional kind of exposure guidance values for workers; namely, the derived no effect level (DNEL) for workers' inhalation exposure (worker DNEL). About 500 substances have a Swedish OEL, while roughly 5000 substances have a worker DNEL derived by REACH registrants. This work aims to investigate how the Swedish OELs and worker DNELs are perceived at Swedish workplaces, and whether worker DNELs are considered a possible alternative to OELs when the latter are lacking. Material and Methods: An online questionnaire was designed and sent to Swedish companies identified through the European Chemicals Agency's database of registered substances $(\mathrm{N}=126)$ and the Swedish Chemicals Agency's registry of companies that import or manufacture notifiable chemical products $(\mathrm{N}=227)$. The response rates were $52 \%$ and $38 \%$, respectively. Results: The respondents stated that they were using the Swedish OELs and most of them considered these to be a suitable risk management tool. As about one-third of the respondents expressed that they had some experience in using substances without the Swedish OELs, there are certain data gaps that worker DNELs may fill. One-third of the respondents familiar with worker DNELs stated that they would consider using worker DNELs for substances without the Swedish OELs. However, nearly half of the respondents reported to be unfamiliar with worker DNELs. Conclusions: Poor familiarity with DNELs may pose an obstacle to properly recognizing DNELs' potential as well as the possible limitations of individual DNELs. There is a need for education about DNELs, as well as for tools facilitating the evaluation of DNELs and OELs from other sources in cases where the applicable Swedish OEL is lacking. Int J Occup Med Environ Health. 2020;33(5):611-20
\end{abstract}

Key words:

occupational health, chemicals, legislation, MAC, toxic industrial agents, chemical risk management

Funding: this work was supported by AFA Insurance (grant No. 160032 entitled "Could DNELs complement Swedish OELs for substances with poor knowledge base?," project manager: Linda Schenk).

Received: May 20, 2019. Accepted: April 21, 2020.

Corresponding author: Linda Schenk, Karolinska Institutet, Integrative Toxicology, Institute of Environmental Medicine, Box 210, 17177 Stockholm, Sweden (e-mail: linda.schenk@ki.se). 


\section{INTRODUCTION}

Within the EU, a number of directives targeting the work environment are in place. The basic occupational health and safety requirements are laid out in the Framework Directive [1]. Additional directives that more specifically regulate occupational exposure to chemicals have been adopted under the Framework Directive; notably, the Chemical Agents Directive [2], the Carcinogens and Mutagens Directive [3], as well as a series of directives establishing lists of occupational exposure limits (OELs). In addition, OELs are derived nationally by several EU member states; however, both the procedures and levels may differ from those of EU OELs. In Sweden, the national OELs are promulgated by the Swedish Work Environment Authority (SWEA), and the most recent OEL list was published in 2018 [4]. While SWEA dissolved its national expert group for OELs, referred to as the Swedish Criteria Group, in 2016, it still coordinates the joint expert group for the Nordic countries (the Nordic Expert Group).

The objective of OELs is to protect workers' health by stipulating a maximum allowable air-borne concentration of a hazardous substance. Generally, OELs are performance standards. How the exposures are limited is up to the individual workplaces to determine, although the implementation of risk management measures is expected to adhere to a hierarchy of control measures [2]. Previous research from Sweden, targeting a general sample of the Swedish population of working age that self-identified as exposed to any kinds of air pollutants, showed that the knowledge of Swedish OELs is incomplete [5]. For instance, while $88 \%$ of the respondents knew that Swedish OELs were set for the purpose of protecting human health, only $39 \%$ knew that these OELs were legally binding. Persons that identified themselves as being in managerial positions scored generally higher on questions referring to OEL knowledge. However, even among this latter group, $54 \%$ reported to know too little of the Swedish
OELs to have an opinion on their effect on occupational health [5]. In interview studies specifically targeting work environment professionals and safety representatives, it was found that the OELs from SWEA were trusted as well as considered useful and needed for chemical safety management at Swedish workplaces [6,7].

Another important piece of legislation on chemical safety which applies broadly, and is not limited to but includes work environment, is the EU Regulation on Registration, Evaluation, Authorisation and Restriction of Chemicals (REACH) [8]. Under REACH, there is an exposure guidance value similar to the OEL, namely the derived no effect level (DNEL) for workers' inhalation exposures (worker DNEL) [8,9]. Under REACH Registration, manufacturers and importers of chemical substances derive DNELs. Under REACH Authorisation and Restriction, also the European Chemical Agency's Committee for Risk Assessment (ECHA RAC) may derive DNELs. Generally, DNELs are intended to serve as a benchmark for evaluating whether the risk of a particular exposure is adequately controlled. Registrants are obliged to identify permissible uses and required risk management measures, and to communicate these to downstream users through safety data sheets (SDSs) and exposure scenarios (only for extended SDSs [8]). The DNELs are defined as representing levels at which no harmful effects to health are to be expected [8], i.e., they apply to substances with threshold effects. For non-threshold effects, the REACH guidance [10] instead recommends a derived minimal effect level (DMEL). However, unlike DNELs, DMELs are not defined in REACH [8] and thus will not be discussed further in the present paper.

While worker DNELs and OELs are derived under different legislations and are intended for different functions related to workplace risk management, both are presented as numerical values of airborne concentrations below which workers' health should be protected from adverse effects. It seems likely that some confusion 
between the 2 measures may ensue [11-13]. However, the body of DNELs should also be recognized as a knowledge resource regarding exposure guidance values [14], not the least because REACH registrants have provided worker DNELs for approximately 5000 substances [15], while the regulatory lists of OELs cover around 500 substances [4].

With the resources assigned to the national OEL setting reduced by SWEA, OELs may decline in importance for risk management of chemicals at Swedish workplaces. The author has thus hypothesized that worker DNELs may become an alternative source of exposure guidance values. However, the absolute values may vary considerably, among others, due to differences in the way OELs and worker DNELs are derived $[9,13]$. While for some substances, worker DNELs are more recent and seemingly more precautionary (although lower does not necessarily mean more reliable) than their corresponding OELs [9,12], for other substances, grossly misleading worker DNELs have been identified [9]. Thus, worker DNELs may contribute with important risk information, but as of yet they require case-by-case evaluation of reliability.

The aim of the present work was to investigate how OELs and worker DNELs are perceived by Swedish professionals working with chemicals-related health and safety in the workplace. More specifically, the author addressed the following questions:

- How are Swedish OELs perceived and used?

- To what extent are these professionals aware of worker DNELs?

- Are worker DNELs seen as a potential alternative when Swedish OELs are lacking?

To this end, an online questionnaire was designed and sent out to Swedish companies that were part of 1 or several REACH registrations, and a sample of Swedish companies that have reported to import or manufacture notifiable chemical products.

\section{MATERIAL AND METHODS}

\section{Selection of respondents}

Two different databases were used to identify prospective respondents. The first was the ECHA database on registered chemicals [16], from which the author extracted all registrations including Swedish registrants (July 5, 2018, N = 869), identifying 126 Swedish individual importers or manufacturers. All of these were included in the send-list. In addition, the author used the Swedish Chemical Agency's registry of products and companies using chemicals [17]. In early July 2018, this database contained 2226 Swedish companies that imported or manufactured notifiable chemical products (according to the Chemical Products and Biotechnical Organisms Ordinance [18]). The author randomly sampled 227 companies from this registry, excluding registrants and companies that, according to publicly available company details, only imported and resold chemical products.

\section{Questionnaire}

The questionnaire builds upon previous studies $[5,7,19]$ and consisted of a mixture of closed (yes/no and multiple-choice) and open-ended questions. Two colleagues with an occupational hygiene background commented on the draft and additional 2 laypersons were asked for advice on the clarity of language. Data collection was performed through an online questionnaire, created using the Artologik Survey and Report software. The following topics were covered:

- demographic and workplace information,

- familiarity with, use of and opinion about Swedish OELs as a risk management tool,

- familiarity with REACH and DNELs,

- opinion about DNELs as a risk management tool with a potential to complement OELs.

Invitation letters addressed to work environment/chemical managers were sent out by post at the beginning of September 2018 using the registrants send-list, and 10 days later using the product registry send-list. The letter con- 
tained information about the study, how the company had been identified, and a customized, easy to type, link to the online questionnaire. The letter specified that the author wished for a person responsible for chemical health and safety at the workplace to fill in the questionnaire. The questionnaire also contained additional information about the study and about the informed consent. Data collection was anonymous. Postal reminders were sent out after 1 month. The questionnaire was closed at the end of October 2018 for the registrants send-list and in mid-November 2018 for the product registry send-list.

\section{Analysis}

Categories for the coding of the open-ended questions were identified inductively through repeated close readings. As the level of abstraction was low, i.e., the interpretation for the coding was close to the text, 1 coding author was considered sufficient.

Table 1. Characteristics of the respondents to the questionnaire sent out to work environment/chemical managers at Swedish companies in September-November 2018

\begin{tabular}{|c|c|c|}
\hline \multirow[t]{2}{*}{ Variable } & \multicolumn{2}{|c|}{$\begin{array}{c}\text { Respondents } \\
(\mathrm{N}=152) \\
{[\mathrm{n}(\%)]}\end{array}$} \\
\hline & $\begin{array}{l}\text { REACH registrant respondents } \\
\qquad(\mathrm{N}=65)\end{array}$ & $\begin{array}{l}\text { product registry respondents } \\
\qquad(\mathrm{N}=87)\end{array}$ \\
\hline \multicolumn{3}{|l|}{ Gender } \\
\hline female & $37(57)$ & $35(40)$ \\
\hline male & $27(42)$ & $52(60)$ \\
\hline mixed* & $1(2)$ & $0(0)$ \\
\hline \multicolumn{3}{|l|}{ Education } \\
\hline secondary education (upper) & $8(12)$ & $26(30)$ \\
\hline post-secondary vocational education & $5(7)$ & $5(6)$ \\
\hline tertiary education & $52(78)$ & $55(63)$ \\
\hline other & $0(0)$ & $1(1)$ \\
\hline \multicolumn{3}{|l|}{ Position at the company** } \\
\hline OHS engineer & $24(37)$ & $9(10)$ \\
\hline OHS coordinator & $12(18)$ & $17(20)$ \\
\hline chemist & $4(6)$ & $3(3)$ \\
\hline occupational hygienist & $2(3)$ & $0(0)$ \\
\hline site/production manager & $5(8)$ & $8(9)$ \\
\hline SHEQ manager & $13(20)$ & $33(38)$ \\
\hline owner/CEO & $0(0)$ & $10(11)$ \\
\hline other & $5(8)$ & $7(8)$ \\
\hline
\end{tabular}

CEO - chief executive officer; OHS - occupational health and safety; REACH - the Regulation on Registration, Evaluation, Authorisation and Restriction of Chemicals; SHEQ - safety, health, environment and quality.

* This respondent commented that the questionnaire was filled in by several respondents from the same workplace.

** This was a multiple-choice question with an option to also provide a free-text description. The grouping presented is the author's.

The SHEQ manager item also includes the respondents stating to be responsible for 2 or 3 of the areas (e.g., SHE or EQ). 


\section{RESULTS}

The author received 65 answers from the registrant sendlist and 87 answers from the product registry send-list, yielding the response rates of $52 \%$ and $38 \%$, respectively. However, it should be noted that there may be $>1$ person per respondent, i.e., several persons answering together (1 respondent explicitly commented this was the case Table 1 ) or potentially $>1$ respondent per invited workplace; the author did not control for this. Overall, about $50 \%$ of the respondents were female although gender division differed somewhat between the groups (Table 1). Also, the reported levels of education differed somewhat between the respondent groups, but for both tertiary education was the most commonly reported (Table 1).

Almost all the respondents stated to be at least somewhat familiar with OELs (Figure 1). A larger share of product registry respondents than registrant respondents reported not to use OELs in their work (Figure 1). A majority of the respondents from both groups reported that they considered "performing workplace exposure measurements and comparing them to the level of the OEL" to constitute their use of an OEL (Figure 2). This was also the most common kind of use reported by the respondents from the registrant group. Almost as frequently considered as the use of an OEL was to "follow the instructions on safe use in the safety data sheets" (Figure 2). Less common were the 2 approaches of "modeling exposure by use of computer software" or "to extrapolate from exposure measurements performed at similar (i.e., equivalent conditions) workplaces," the so-called reference measurements. For these 2, the difference between reporting to "consider as a use" and reporting "to employ" were also comparably more pronounced. Reference measurements are an approach accepted by SWEA specifically for quartz dust, and were introduced by the 2015 ordinance on quartz dust [20].

Almost all the respondents reported to find OELs a rather suitable $(29 \%)$ or highly suitable $(58 \%)$ regulatory

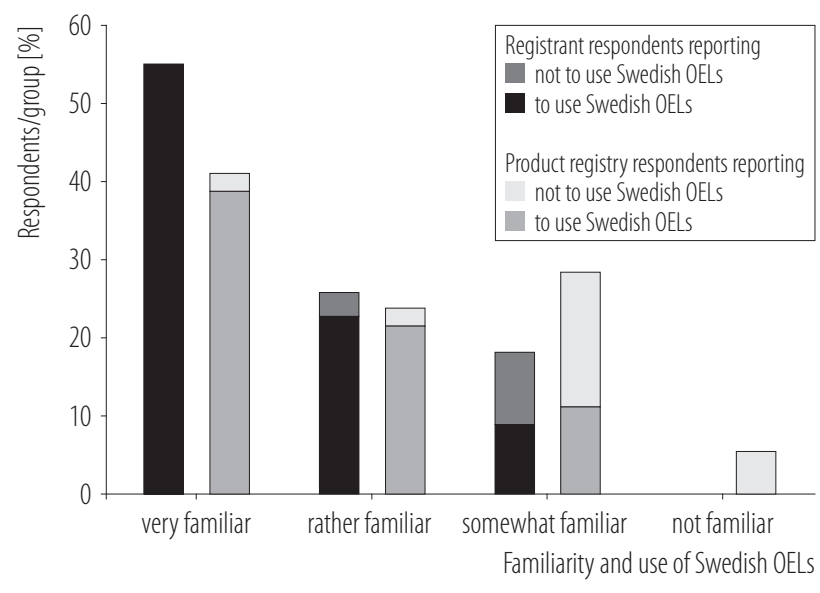

Figure 1. Self-assessed familiarity and reported use of Swedish OELs among registrant respondents $(\mathrm{N}=65)$ and product registry respondents $(\mathrm{N}=87)$, based on the survey conducted among work environment/chemical managers at Swedish companies in September-November 2018

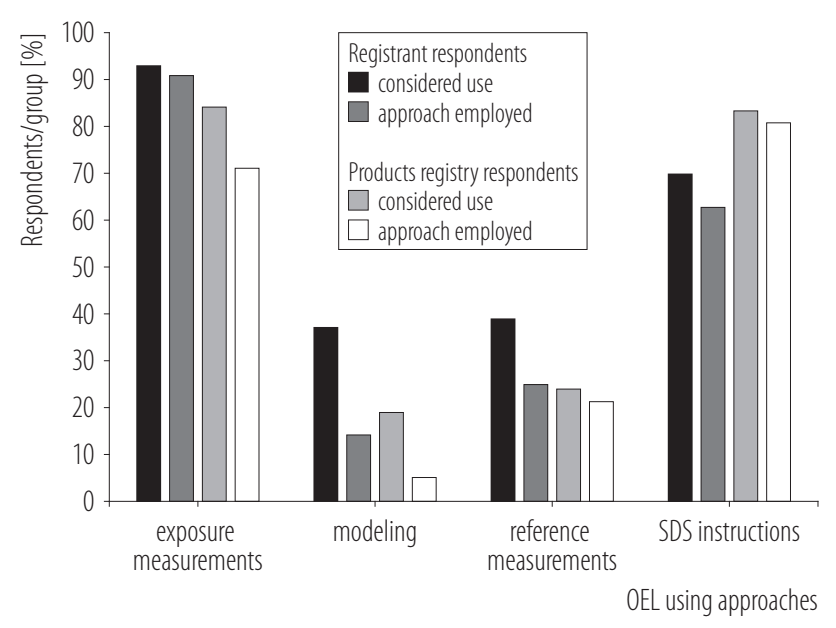

Only including the respondents reporting to use OELs.

Figure 2. The considered uses of OELs and the approaches employed ( $>1$ answer possible) by registrant respondents $(\mathrm{N}=57)$ and product registry respondents $(\mathrm{N}=63)$, based on the survey conducted among work environment/chemical managers at Swedish companies in September-November 2018

risk management tool (Figure 3). In total, $10 \%$ of the respondents replied that they found OELs to be an unsuitable risk management approach, or that they were undecided about its suitability. The respondents were slightly more positive about OELs as a regulatory risk manage- 


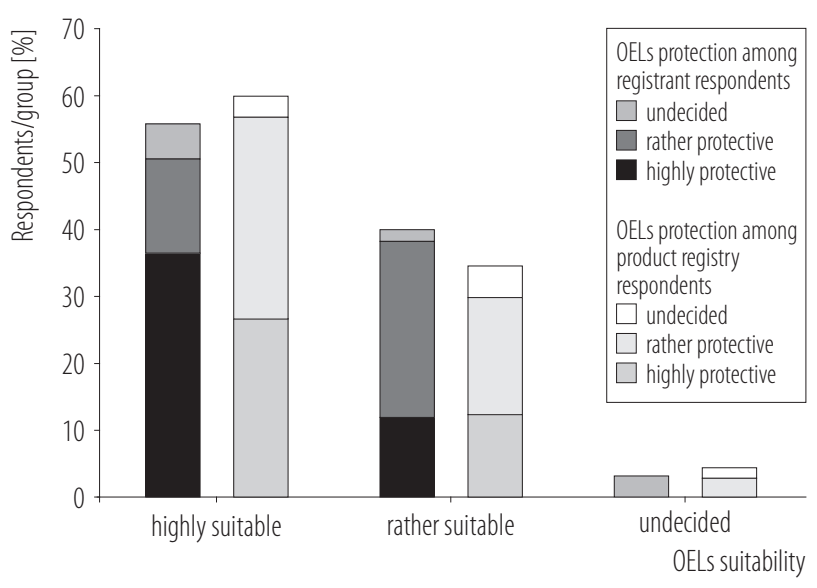

Figure 3. Opinions regarding the suitability of OELs as a risk management tool for the protection of workers' health, and the degree of protection offered by OELs applicable to the respondents' workplace, among registrant respondents $(\mathrm{N}=57)$ and product registry respondents $(\mathrm{N}=63)$, based on the survey conducted among work environment/chemical managers at Swedish companies in September-November 2018

ment tool than about the degree of protection offered by the OELs applicable to their workplaces, as $49 \%$ stated that the OELs applicable to their workplace were highly protective of workers' health (Figure 3).

The respondents were generally familiar with REACH; all the registrant respondents stated to be at least a little familiar with $\mathrm{REACH}$, and for the product registry respondents, the corresponding share was $98 \%$. However, the DNELs derived under this regulation were still relatively unfamiliar to the respondents (Figure 4). In fact, $41 \%$ of the registrant respondents and $53 \%$ of the product registry respondents stated to be unfamiliar with REACH DNELs. The more familiar the respondents stated to be with REACH DNELs, the more likely it was for them to perceive these to have affected their work with occupational health and safety issues (Figure 4). Among the respondents familiar with DNELs, 53\% of the registrant respondents and $63 \%$ of the product registry respondents stated that they found DNELs to be a suitable risk man-

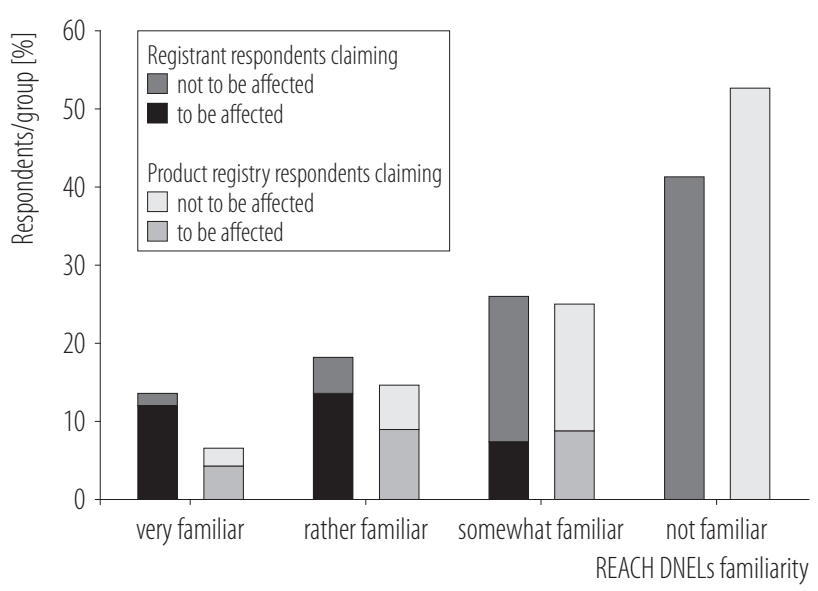

Figure 4. Self-assessed familiarity with REACH DNELs among registrant respondents $(\mathrm{N}=65)$ and product registry respondents $(\mathrm{N}=87)$, and information whether DNELs have affected the respondents' work with occupational health and safety, based on the survey conducted among work environment/chemical managers at Swedish companies in September-November 2018

agement approach to protect people from occupational risks of chemicals (Figure 5).

Turning to the potential of worker DNELs to complement OELs, about 1 in 3 respondents stated to ever have found an OEL lacking for a particular substance (19 out of 57 registrant respondents and 19 out of 63 product registry respondents). In the free-text comments $(\mathrm{N}=21)$, substances and exposure conditions such as hardwood, mixed exposures with respect to metals, petroleum products and cutting fluids were raised. The respondents were asked twice, in different frames, about their attitude towards worker DNELs as a complement to OELs. In response to the first question, posed in connection to the question about the substances lacking Swedish OELs, $21 \%$ of the respondents stated that they would consider worker DNELs in case a substance was lacking a Swedish OEL (15 out of 57 registrant respondents and 10 out of 63 product registry respondents). This question included different approaches, such as looking for other countries' OELs, 


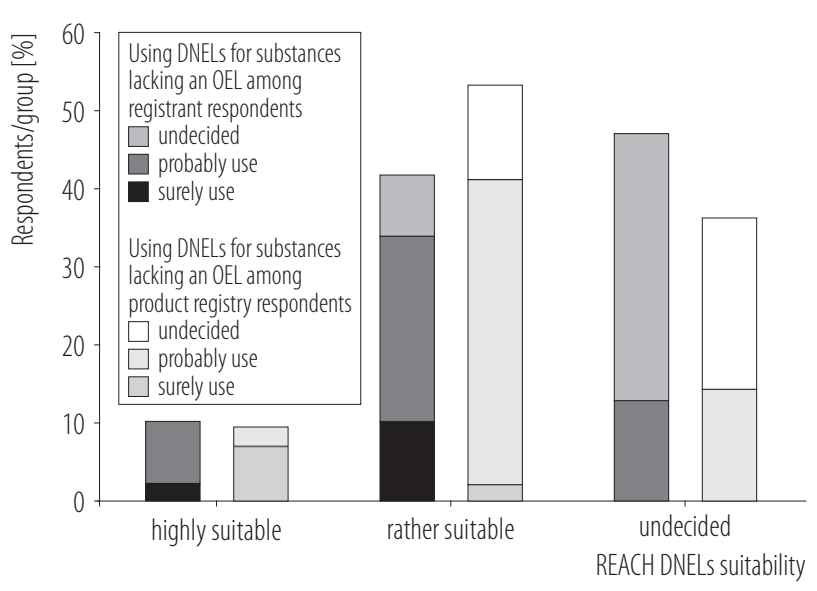

Figure 5. Opinions regarding the suitability of REACH DNELs as a risk management tool for protection of workers' health among registrant respondents $(\mathrm{N}=38)$ and product registry respondents $(\mathrm{N}=41)$, and information whether the respondents would consider using DNELs for substances lacking OELs, based on the survey conducted among work environment/chemical managers at Swedish companies in September-November 2018

and $66 \%$ stated that they preferred to establish safe use of a chemical product by following the instructions provided in the SDS (36 out of 57 registrant respondents and 43 out of 63 product registry respondents).

The second question was placed after assessing the awareness and suitability of worker DNELs as a risk management tool. Here, $62 \%$ of the respondents stating to be familiar with worker DNELs also stated that they would consider using a DNEL in case a Swedish OEL was missing (22 out of 38 registrant respondents and 27 out of 41 product registry respondents - Figure 5). The respondents switching positions thus went from not considering a worker DNEL in the SDS/OEL frame, to be undecided or positive towards this in the DNELs alone frame. Across the 2 questions, $30 \%$ consistently answered that they would consider worker DNELs as an alternative to OELs (12 out of 36 registrant respondents and 10 out of 37 product registry respondents, only including the respondents answering both questions).

\section{DISCUSSION}

This survey targeted companies actively using chemical products and, in particular, professionals involved in occupational risk management of these. Consequently, almost all the respondents were familiar with OELs, although not all, in particular among the product registry respondents, reported to actively use OELs themselves. It is interesting to note that a comparison to the results from exposure measurements is most frequently reported as a considered use, and in the case of the registrant respondents also the most frequently reported approach. In the light of the criticisms that have been voiced against SDSs in different contexts [7], it was unexpected that a high share of respondents reported to consider adherence to SDS instructions on the allowed uses and prescribed risk management measures as using an OEL, while at the same time only few reported computer modeling as a means to use OELs. Exposure modeling is a still developing field and the practical knowledge of how to apply these tools is likely lacking among the respondents. The lack of practical know-how could also explain the fact that the gap between "considered as a use" and "the employed use" is comparably larger for modeling than the other approaches to using an OEL.

Trust in Swedish OELs seems to be high among the respondents from both groups under consideration. However, approximately one-third of the respondents had at times found the Swedish list of OELs to lack an OEL for 1 or several substances. This lack of OELs could be a reason to turn towards REACH and DNELs as alternative sources of exposure guidance values. However, among the respondents, 2 out of 5 registrant respondents and half of the product registry respondents stated to be unfamiliar with DNELs. This is a striking finding, as REACH has been in place for $>10$ years, and the third and final registration deadline for REACH was May 31, 2018, just a few months prior to the distribution of this questionnaire. A similar finding was recently made regarding 
the awareness of DNELs among health and safety professionals in the Netherlands [19]. This poor awareness needs to be given attention because DNELs, regardless of the potential objections about their reliability [9,11], are an important part of the legislative framework on the protection of workers' health.

Turning to opinions on the reliability of DNELs for workers as a risk management tool for the protection of workers' health, the respondents claiming to be familiar with DNELs mainly reported either to find them rather suitable or to be undecided. This can be compared with the same question for OELs where the majority of the respondents stated OELs to be a highly suitable tool, and few claimed to be undecided. The share of the respondents that would consider using corresponding worker DNELs for substances lacking OELs increased over the course of the survey, from $21 \%$ when asked in the context of OELs, to one-third when asked in the context of REACH and DNELs. Whether an effect of the question framing or a habituation to the idea, this discrepancy shows that most of the respondents do not have firm opinions on DNELs. While clearly not an unconditional acceptance of DNELs as a suitable replacement for OELs, some occupational health and safety professionals, as was also the case in the Netherlands [19], do consider them as replacements when regulatory OELs are missing.

It should be pointed out that the national OELs are the baseline, in the sense that these are the regulatory OELs, not necessarily in the sense of always being a more reliable exposure guidance value from the toxicological and medical perspective. First, for any kind of an exposure guidance value, there are a number of epistemological limitations [21]. Second, many works have pointed out some inconsistencies, the lack of transparency [22], as well as an insufficient degree of protection for OELs [23,24]. While $>50 \%$ of worker DNELs are set to a more restrictive level than OELs for the same substance $[9,14]$, there are also some examples of clearly misleading values [9].
At the same time, the degree of detail given in the scientific basis of worker DNELs varies widely, making it difficult for third parties to evaluate the reliability of DNELs [9]. The transfer of responsibilities for providing a scientific basis of OELs from the Scientific Committee on Occupational Exposure Limits to ECHA RAC [25], and the publication of an OEL derivation methodology as an appendix to chapter R.8 on DNEL derivation [26], may further reduce the perceived distance between OELs and DNELs. These developments underline the need for an improved transparency and a continued review of reliability of DNELs.

\section{CONCLUSIONS}

The respondents state to use the Swedish OELs and, in general, find these to be a suitable risk management tool. However, there are certain limitations in the coverage of the list of Swedish OELs. Worker DNELs derived under REACH may fill certain gaps, but poor familiarity with DNELs may be an obstacle to properly recognizing worker DNELs' potential as well as the possible limitations of individual DNELs. The author thus sees a need for education about DNELs and tools facilitating the evaluation of reliability of DNELs and OELs from other sources in case a suitable Swedish OEL is missing.

\section{ACKNOWLEDGMENTS}

The author would like to thank Nicole Palmen and Anneli Julander for their feedback on questionnaire design. The author is also grateful to Ann-Katrin Sjödén and Artur Podobas for their feedback on questionnaire clarity. Ann-Katrin Sjödén also assisted with questionnaire distribution.

\section{REFERENCES}

1. Council Directive of 12 June 1989 on the introduction of measures to encourage improvements in the safety and health of workers at work (89/391/EEC). Off J Eur Union 183, p. 1-8 (Jun 29, 1989). 
2. Council Directive 98/24/EC of 7 April 1998 on the protection of the health and safety of workers from the risks related to chemical agents at work (fourteenth individual Directive within the meaning of Article 16(1) of Directive 89/391/ EEC). Off J Eur Union 131, p. 11-23 (May 5, 1998).

3. Directive 2004/37/EC of the European Parliament and of the Council of 29 April 2004 on the protection of workers from the risks related to exposure to carcinogens or mutagens at work. Off J Eur Union 229, p. 23-34 (Jun 29, 2004).

4. Swedish Work Environment Authority. Hygieniska gränsvärden [Occupational Exposure Limits] AFS 2018:1. Stockholm: The Authority; 2018. Swedish.

5. Schenk L. Awareness and understanding of occupational exposure limits in Sweden. Regul Toxicol Pharmacol. 2013;65:304-10, https://doi.org/10.1016/j.yrtph.2013.01.006.

6. Schenk L, Wester M. Covert chemicals, tangible trust. Chemicals risk management at the workplace. Policy Pract Health Saf. 2014;12(1):91-106, https://doi.org/10.1080/1477 4003.2014.11667799.

7. Schenk L, Antonsson A-B. Implementation of the chemicals regulation REACH - Exploring the impact on occupational health and safety management among Swedish downstream users. Saf Sci. 2015;80:233-42, https://doi.org/10.1016/j.ssci. 2015.08.001.

8. Regulation (EC) no 1907/2006 of the European Parliament and of the Council of 18 December 2006 concerning the Registration, Evaluation, Authorisation and Restriction of Chemicals (REACH). Off J Eur Union 396, p. 1-849 (Dec 30, 2006).

9. Schenk L, Johanson G. Will worker DNELs derived under the European REACH regulation extend the landscape of occupational exposure guidance values. Arch Toxicol. 2019;93(5): 1187-200, https://doi.org/10.1007/s00204-019-02439-0.

10. European Chemicals Agency. Guidance on information requirements and chemical safety assessment. Chapter R.8: Characterisation of dose [concentration]-response for human health. November 2012. Version 2.1. Helsinki: The Agency; 2012.
11. Gromiec J. [Problems concerning the integration of "Derived No Effect Levels" (DNELs) into occupational safety and health regulations]. Med Pr. 2008;59(1):65-73. Polish.

12. Kupczewska-Dobecka M, Swiercz R. [Setting limit values for chemical substances in the workplace: DNEL(INH) setting according to REACH principles following the example of 2-butyne-1,4-diol]. Med Pr. 2009;60(5):347-57. Polish.

13. Schenk L, Johanson G. A quantitative comparison of the safety margins in the european indicative occupational exposure limits and the derived no-effect levels for workers under REACH. Toxicol Sci. 2011;121(2):408-16, https://doi. org/10.1093/toxsci/kfr056.

14. Nies E, Musanke U, Püringer J, Rühl R, Arnone M. DNELs for workplaces - observations from an inspection of the DGUV DNEL list. Gefahrst Reinhalt L. 2013;73(11/12):455-62.

15. GESTIS DNEL list. Sankt Augustin: IFA - Institute for Occupational Safety and Health of the German Social Accident Insurance. November 2018 [cited 2019 May 19]. Available from: https://www.dguv.de/ifa/gestis/gestis-dnel-liste/ index-2.jsp.

16. European Chemical Agency [Internet]. The Agency; 2019 [cited 2018 Jul 5]. Database on registered chemicals. Available from: https://echa.europa.eu/sv/information-on-chemicals/registered-substances.

17. The Swedish Chemicals Agency's Company Register. Sundbyberg: The Agency; 2019 [cited 2019 May 19]. Available from: https://webapps.kemi.se/foretagsregistret/.

18. Sweden Ministry of Environment and Energy. Chemical Products and Biotechnical Organisms Ordinance 2008:245. Stockholm: The Authority; 2008.

19. Schenk L, Visser M, Palmen NGM. Industry Derived Occupational Exposure Limits: A survey of Professionals on the Dutch System of Exposure Guidelines. Ann Work Expo Health. 2019;63(9):1004-12, https://doi.org/10.1093/annweh/ wxz069.

20. Swedish Work Environment Authority. Kvarts - stendamm i arbetsmiljön [Quartz - stone dusts in the work environment]. AFS 2015:2. Stockholm: The Authority; 2015. 
21. Fairhurst S. Hazard and risk assessment of industrial chemicals in the occupational context in Europe: some current issues. Food Chem Toxicol. 2003;41:1453-62, https://doi.org/ 10.1016/S0278-6915(03)00193-5.

22. Schenk L, Johanson G. Use of Uncertainty Factors by the European Commission Scientific Committee of Occupational Exposure Limits: A follow up. Crit Rev Toxicol. 2018;48(7): 513-21, https://doi.org/10.1080/10408444.2018.1483891.

23. Cherrie JW, Brosseau LM, Hay A, Donaldson K. Low-Toxicity Dusts: Current Exposure Guidelines Are Not Sufficiently Protective. Ann Occup Hyg. 2013;57(6):685-91, https://doi.org/10.1093/annhyg/met038.
24. Johanson G, Tinnerberg H. Binding occupational exposure limits for carcinogens in the EU- good or bad? Scand J Work Environ Health. 2019;45(3):213-4, https://doi.org/10.5271/sjweh.3825.

25. European Chemicals Agency [Internet]. The Agency [cited 2019 May 19]. ECHA to provide recommendations for occupational exposure limits. ECHA/PR/19/02. Available from: https://echa.europa.eu/-/echa-to-provide-recommendationsfor-occupational-exposure-limits.

26. European Chemicals Agency. Appendix to Chapter R.8: Guidance for preparing a scientific report for health-based exposure limits at the workplace. Draft Public version 3.0. March 2019. Helsinki: The Agency; 2019.

This work is available in Open Access model and licensed under a Creative Commons Attribution-NonCommercial 3.0 Poland License - http://creativecommons.org/ licenses/by-nc/3.0/pl/deed.en. 